\title{
Guest Editor's Introduction to the Special Section on Nonverbal Aspects of Mate Choice and Courtship
}

\section{J. Michael Bailey}

Published online: 13 August 2011

(C) Springer Science+Business Media, LLC 2011

The invited articles in this special section were initially part of a symposium entitled "Nonverbal Aspects of Mate Choice and Courtship," which occurred at the Fifth International Anthropological Congress of Aleš Hrdlička in Prague, Czech Republic, September $2-5,2009$. The main aim of the symposium was to bring together scholars who use evolutionary theory as a conceptual framework for their research on mate choice and courtship. Represented disciplines included anthropology, psychology, human ethology, and biology. The symposium included 2 plenaries, 20 oral presentations, 12 poster presentations, 2 round table discussions, and one workshop. The symposium was convened by Jan Havlíček of Charles University and Vladimír Blažek of the University of West Bohemia. Articles were reviewed by the Guest Editor and the Editor and other members of the Editorial Board.

J. M. Bailey ( $₫)$

Department of Psychology, Northwestern University, 2029

Sheridan Road, Swift Hall \#102, Evanston, IL 60208-2710, USA

e-mail: jm-bailey@northwestern.edu 